\title{
Microencapsulation of avocado pear seed (Persea Americana mill) bioactive-rich extracts and evaluation of its antioxidants, in vitro starch digestibility and storage stability
}

\author{
Olugbenga O. Awolu ${ }^{1 *} \mathbb{B}$, Esosa T. Fole ${ }^{1}$, Oluwatoyin A. Oladeji ${ }^{2}$, Helen N. Ayo-Omogie ${ }^{1}$ and \\ Aderonke I. Olagunju ${ }^{1}$
}

\begin{abstract}
Background: This study evaluated the antioxidant activities of avocado seed extract as affected by solvent for extraction and formulation of microcapsule from the extract. Avocado seed powder was extracted using ethanol, aqueous ethanol, and water as solvents. The extract with the highest bioactive activity was encapsulated using corn and cassava starches as cell wall materials. The antioxidant activity, storage stability, in vitro starch digestibility and Fouriertransform infrared spectroscopy (FTIR) of the microcapsules were evaluated.

Results: Results indicated that 100\% ethanolic extract had the highest flavonoid and total phenolic contents and the highest antioxidant activity. Cassava starch was observed as a better cell wall material for the entrapment of phenolic and bioactive compounds as compared to corn starch. After 30 days of storage at room temperature, there was a significant reduction $(p \leq 0.05)$ in the DPPH and $\mathrm{OH}^{*}$ of the microcapsules, while the total phenol contents increased significantly $(p \leq 0.05)$. The FTIR showed that the microcapsules contained primarily alcohol $(\mathrm{O}-\mathrm{H})$, carbonyl, $(C=\mathrm{O}$,$) ,$ alkyne $(\mathrm{C} \equiv \mathrm{C})$ and benzene ring functional groups. The microcapsules were able to retain the bioactive contents during storage.
\end{abstract}

Conclusion: Microcapsule produced could be used for the formulation of several functional food products and supplements.

Keywords: Antioxidant, Avocado seed extract, Cell wall material, FTIR, Food wastes, In vitro starch digestibility, Microencapsulation

\section{Background}

Recently, increased incidence of chronic metabolic diseases has been linked to lifestyle changes and the use of synthetic drugs for treatment and management of these conditions has been associated with adverse effects. However, functional diets rich in plant-based foods have been suggested as a safer strategy for

\footnotetext{
${ }^{*}$ Correspondence: ooawolu@futa.edu.ng

${ }^{1}$ Department of Food Science and Technology, Federal University

of Technology, Akure, Nigeria

Full list of author information is available at the end of the article
}

managing these diseases due to the presence of high bioactive compounds in the plants (Awolu and Oladeji 2021; Ogundele et al. 2016). Furthermore, lowered risk of many of these diseases has been linked to the consumption of plant-based functional diets. This has recently, increased the demand for functional foods and supplements with bioactive components due to their health-promoting properties (Awolu and Oladeji 2021). However, most of the commercially available functional foods and nutraceuticals are expensive and usually not affordable for the most segment of the population, 
especially in developing countries where poverty is high and on the increase. As such, recent research interest has been directed at exploring locally available plants as low-cost raw materials for the development of functional foods and nutraceuticals.

Interestingly, several food wastes are rich in bioactive compounds and so are being employed in the preparation of functional foods (Awolu and Osigwe 2019; Awolu et al. 2016; Sharma et al. 2017). Furthermore, several low-cost locally available underutilized crops and food wastes have been found to possess a potential for the development of low-cost functional foods and nutraceuticals (Naik et al. 2010; Ayala-Zavala et al. 2011). This, on the other hand, reduces the negative impacts of wastes on the environment and the health of the people.

Food nanotechnology has become a vital tool for increasing the effectiveness of the use of nutraceuticals. This is because food nanotechnology ensures the bioavailability of the bioactive compounds at micro- and nano-scales (Awolu and Manohar 2019), thereby promoting controlled release of the encapsulated nutrient to targeted sites (Shahidi and Han, 1993). Approximately, $20 \%$ of identified plants have been used in pharmaceutical studies, impacting the healthcare system in positive ways such as treatment of cancer and harmful diseases (Naczk and Shahidi 2006). Plants comprising of beneficial phytochemicals may supplement the needs of the human body by acting as natural antioxidants (Panche et al. 2015).

Avocado pear (Persea Americana Mill.) is an evergreen tropical and subtropical fruit, rich in oil, and traditionally cultivated for food and medicinal purposes due to its high nutritional properties (Ding et al. 2007). Avocado pear has also been reported to possess anticancer activity (Lu et al. 2005). Avocado by-products, mainly peel and seed are usually discarded as wastes. They are, however, sources of important phytochemical compounds (Melo et al 2015; Saavedra et al 2017). Avocado seed by-products also contain large quantities of extractable polyphenols which have attracted the attention of food and cosmetic industries due to their high antioxidant capacity (Segovia et al. 2016). Although studies have been carried out on the nutritional and functional properties of avocado waste (the seed), as well as the inhibitory effect of the phenolic content of the fruit (Tremocoldi et al. 2018), there is a dearth of information on the suitability, bioavailability and effectiveness of the seed antioxidant components as nutraceuticals. Hence, this study was carried out to evaluate the usefulness of avocado pear seed, as nutraceuticals, by encapsulation. Digestibility and stability of different cell wall materials of varied ratios for the production of microcapsules were also investigated.

\section{Methods}

Collection and authentication of materials

Avocado fruit (Persea Americana Mil) was purchased from new Benin market, Edo state Nigeria.

The species was authenticated at the Department of Crop, Soil and Pest Management, Federal University of Technology Akure, Ondo State, Nigeria. All chemicals used for the analysis were of analytical grade.

\section{Preparation of avocado seed powder}

Mature, fresh green avocado fruits (Persea Americana Mil) were washed with tap water, drained and packed into a black polyethylene bag until ripen. The seeds of ripe avocado fruits were manually separated from the pulp, thoroughly washed, cleaned, sliced and sundried for 3 to 5 days and thereafter packed in an airtight plastic container. The dried seeds were milled using hammer mill (Model, YL-90L-40), and the avocado seed powder obtained was packed in an airtight plastic container and stored at room temperature until further use.

\section{Extraction of avocado seed extract}

The method described by Awolu et al. (2013) with slight modification was used for extraction of the seed. About $50 \mathrm{~g}$ of the avocado seed powder was weighed and defatted in a soxhlet apparatus. The extraction was carried out using different solvents and solvent ratios (100\% ethanol, $50 \%$ aqueous ethanol and $100 \%$ water). Excess solvent after extraction was removed in a rotary evaporator (Buchi R-210, Flawil, Switzerland). The extracts obtained were stored in an air tight bottle in a laboratory fridge prior to further analysis.

\section{Determination of total phenolic and total flavonoid content}

The total phenol of the extracts were determined using Folin-Ciocalteu method as described by Singleton et al., (1999). Exactly $0.2 \mathrm{~mL}$ of each sample extract were measured into a test tube and mixed with $2.5 \mathrm{~mL}$ of $10 \%$ Folin ciocalteau's reagent and $2 \mathrm{~mL}$ of $7.5 \%$ sodium carbonate. The reaction mixture was subsequently incubated at $45^{\circ} \mathrm{C}$ for $40 \mathrm{~min}$, and the absorbance was measure at $700 \mathrm{~nm}$ in the spectrophotometer. Garlic acid was used as standard phenol and total phenol was estimated with the expression:

$$
\begin{aligned}
& \text { Total phenolic content }(\mathrm{mg} \text { GAE } / \mathrm{g}) \\
& =\frac{\text { Sample } \times \text { conc of standard }(\mathrm{mg} / \mathrm{ml})}{\text { Abs standard } \times \text { sample } \operatorname{cong}(\mathrm{mg} / \mathrm{g})}
\end{aligned}
$$

The total flavonoid content of the extracts was determined using a colorimeter assay developed by Bao et al. (2005). About $0.2 \mathrm{~mL}$ of each of the sample extract were 
measured into a test tube and added to $0.3 \mathrm{~mL}$ of $5 \%$ $\mathrm{NaNO}_{3}$ at zero time. After $5 \mathrm{~min}, 0.6 \mathrm{~mL}$ of $10 \% \mathrm{AICI}_{3}$ was added, and after $6 \mathrm{~min}, 2 \mathrm{~mL}$ of $1 \mathrm{M} \mathrm{NaOH}$ was also added to the mixture followed by the addition of $2.1 \mathrm{~mL}$ of distilled water. Absorbance was read at $510 \mathrm{~nm}$ against the reagent blank and flavonoid content was expressed as mg quercertin equivalent. where $A_{c}$-Absorbance of control; $A_{s}$-Absorbance of sample. TMW = Molecular mass of Trolox (264.32 g/ mol).

The ability of each sample extract to prevent $\mathrm{Fe}^{2+} / \mathrm{H}_{2} \mathrm{O}_{2}$ induced decomposition of deoxyribose was carried out using the method of Halliwell and Gutteridge (1981). Briefly, freshly prepared sample extract $(0-100 \mu \mathrm{l})$ was

Total flavonoid content $(\mathrm{mg} Q E / \mathrm{g})=\frac{\text { Sample } \times \text { conc of standard }(\mathrm{mg} / \mathrm{ml})}{\text { Abs standard } \times \text { sample } \operatorname{cong}(\mathrm{mg} / \mathrm{g})}$

- Abs standard is the absorbance of the solution containing $500 \mu \mathrm{L}$ quercetin, about $50 \mu \mathrm{L} 10 \% \mathrm{AlCl} 3$ and $1 \mathrm{M} \mathrm{CH} 3 \mathrm{COOK}$.

- Blank is the mixture of $500 \mu \mathrm{L}$ of distilled water, $500 \mu \mathrm{L}$ of methanol, $50 \mu \mathrm{L}$ distilled water and $1 \mathrm{M}$ $\mathrm{CH} 3 \mathrm{COOK}$.

\section{Determination of antioxidant activities}

The free radical scavenging ability of the sample extracts against DPPH (2, 2- diphenyl-1-picryhydrazyl) was carried out as described by Gyamfi et al. (1999). About $1 \mathrm{~mL}$ of each sample extract was measured into a test tube and mixed with $1 \mathrm{~mL}$ of the $0.4 \mathrm{mM}$ methanolic solution of the DPPH. The mixture was left in the dark for $30 \mathrm{~min}$ before measuring the absorbance at $516 \mathrm{~nm}$ with spectrophotometer. The percent DPPH radical scavenging activity of the samples were determined using the following equation:

$$
\text { DHHP radical scavenging activity }(\%)=\frac{\mathrm{Abs}_{\mathrm{control}}-\mathrm{Abs}_{\text {sample }}}{\mathrm{Abs}_{\text {control }}}
$$

where Abs $=$ Absorbance.

The ABTS scavenging ability of the extract was determined according to the method described by Re et al. (1999). The ABTS was generated by reacting a $7 \mathrm{mM}$ ABTS aqueous solution with $\mathrm{K}_{2} \mathrm{~S}_{2} \mathrm{O}_{8}(2.45 \mathrm{mM} / \mathrm{L}$, final concentration) in the dark for $16 \mathrm{~h}$ and adjusting the absorbance at $734 \mathrm{~nm}$ to 0.700 with ethanol. Exactly, $0.2 \mathrm{~mL}$ of the appropriate dilution of the extract was then added to $2.0 \mathrm{~mL}$ of ABTS solution, and the absorbance was read at $732 \mathrm{~nm}$ after $15 \mathrm{~min}$. The TROLOX equivalent antioxidant capacity was subsequently calculated using TMW $(264.32 \mathrm{~g} / \mathrm{mol})$. The ABTS scavenging activity was calculated using,

$$
\text { ABTS radical scavenging activity }(\%)=\frac{A_{c}-A_{s}}{A_{c}}
$$

added to a reaction mixture containing $120 \mu \mathrm{L}$ of $20-\mathrm{mM}$ deoxyribose in a test tube, $400 \mu \mathrm{L}$ of $0.1 \mathrm{M}$ phosphate buffer $\mathrm{pH} 7.4,40 \mu \mathrm{L}, 20-\mathrm{mM}$ hydrogen peroxide and $40 \mu \mathrm{L}, 500 \mu \mathrm{M}$ FeSO4, were added and the volume was made up to $800 \mu \mathrm{L}$ with distilled water. The reaction mixture were incubated at $37^{\circ} \mathrm{C}$ for $30 \mathrm{~min}$ and the reaction was stopped by the addition of $0.5 \mathrm{ml}$ of $2.8 \% \mathrm{TCA}$, then followed by the addition of $0.4 \mathrm{ml}$ of $0.6 \%$ TBA solution. The tubes were subsequently incubated in boiling water for $20 \mathrm{~min}$. The absorbance was measured at $532 \mathrm{~nm}$ using spectrophotometer at $10 \mathrm{~min}$ intervals for $1 \mathrm{~h}$. The hydroxyl radical scavenging activity was calculated using the reaction rate $(\mathrm{DA} / \mathrm{min})$ equation.

The ability of each sample extract to chelate $\mathrm{Fe}^{2+}$ were determined using a modified method of Puntel et al. (2005). Briefly, 150-mM FeSO $\mathrm{m}_{4}$ was added to a reaction mixture containing $168 \mathrm{ml}$ of $0.1 \mathrm{M}$ Tris- $\mathrm{HCl} \mathrm{pH} 7.4$ in a test tube, 218-ml saline and extract was added, and then the volume is made up with 1 -ml distilled water. The reaction mixture was incubated for $5 \mathrm{~min}$, before $13 \mathrm{ml}$ of 1, 10-phenantroline was added, and the absorbance was read at $510 \mathrm{~nm}$ using spectrophotometer. The percentage chelating effect (\%) was calculated using the following equation:

$$
\text { Metal chelating activity }(\%)=\frac{\left(1-A_{\text {sample }}\right) \times 100}{A_{\text {blank }}}
$$

$\mathrm{A}=$ Absorbance.

The ferric-reducing power (FRAP) of each samples extract were determined by the method described by Pulido et al. (2003). Exactly, $0.25 \mathrm{ml}$ of each samples extract were measured into a test tube and mixed with $0.25 \mathrm{ml}$ of $200 \mathrm{mM}$ of sodium phosphate buffer $\mathrm{pH}$ 6.6, and then $0.25 \mathrm{ml}$ of $1 \%$ KFC was added. The mixture was incubated at $50{ }^{\circ} \mathrm{C}$ for $20 \mathrm{~min}$; thereafter, $0.25 \mathrm{ml}$ of $10 \%$ TCA was also added and centrifuge at $2000 \mathrm{rpm}$ for 
$10 \mathrm{~min}, 1 \mathrm{ml}$ of the supernatant was mixed with $1 \mathrm{ml}$ of distilled water and $0.1 \%$ of $\mathrm{FeCl}_{3}$ was added. The absorbance was measured at $700 \mathrm{~nm}$ with spectrophotometer.

\section{Encapsulation of avocado seed extract}

The method of Sangeeta et al. (2015) was adopted for encapsulation of the extracts. The crude extract obtained from $100 \%$ ethanol was used for microencapsulation due to its high antioxidant potentials. Appropriate quantity of crude extract was weighed respectively into $250 \mathrm{ml}$ plastic beaker, cell wall materials (corn starch (A) and cassava starch (B)), gum Arabic, Tween 80 and water were weighed respectively into $25 \mathrm{ml}$ plastic beaker (Table 1). Each was mixed evenly inside the beaker with little portion of water added gradually with continuous manual mixing until a liquid mix was obtained. The mixture was homogenized at 12,000 rpm for 7 min using a Lab homogenizer (GEN 700 Cole Parmer). The mixtures were frozen at $-20^{\circ} \mathrm{C}$ in a freezer for $24 \mathrm{~h}$ and lyophilized in a freeze dryer. The freeze dried microencapsulates were thereafter stored in an airtight container at room temperature.

\section{Determination of in vitro starch digestibility of the microencapsulates}

The in vitro starch digestibility of encapsulates were determined using pancreatic amylase and alpha glucosidase according to the method of Englyst et al. (1992). About $50 \mathrm{mg}$ of each sample encapsulate were dispersed in $1 \mathrm{ml}$ of $0.2 \mathrm{M}$ phosphate buffer with $\mathrm{pH}$ 6.9. Then, $20 \mathrm{mg}$ of the enzyme was dissolve in $50 \mathrm{ml}$ of the same buffer, and $0.2 \mathrm{ml}$ of both the sample and enzyme were added, $1 \mathrm{ml}$ of DNSA reagent was added and the mixture was heated for $5 \mathrm{~min}$ in a boiling water bath. After cooling the absorbance of the solution was read at $540 \mathrm{~nm}$ against the blank containing buffer and maltose was used as a standard.

\section{Determination of storage stability of microcapsule}

Microcapsule samples were kept for 30 days at room temperature. The microcapsules were analyzed for DPPH (Gyamfi et al. 1999), metal ions Chelation (Puntel et al. 2005) and total phenol (Singleton et al. 1999) immediately after freeze drying (day Zero) and 30 days after. Moisture content of the microcapsule immediately after freeze drying (day Zero) and 30 days after was also determined using the method described by AOAC (2012).

\section{Fourier transform infrared spectroscopy (FTIR) of the microencapsulate}

The microencapsulates with the highest high antioxidant activities for both corn starch (A2) and cassava starch (B2) wall material were characterized using Fouriertransform infrared spectroscopy (FTIR) (Infrared spectrometer Varian 660 MidIR Dual MCT/DTGS Bundle with ATR). Before analysis, the samples were dried in an auto-desiccator for $24 \mathrm{~h}$. Samples were directly applied to a diamante crystal of ATR and resulting spectra of them were corrected for background air absorbance. Potassium bromide $(\mathrm{KBr})$ disks were prepared from powdered samples mixed with dry $\mathrm{KBr}$ in the ratio of 1:100. The spectra were recorded in a transmittance mode from 4000 to $500 \mathrm{~cm}^{-1}$ wavenumbers at a resolution of $4 \mathrm{~cm}$. Infrared spectrum was Fourier transformed and recorded in the absorption mode. The background spectrum was collected at the beginning of each experimental session in which the selected samples were analyzed in sequence. IR solution software is employed for getting the spectrum.

\section{Statistical analysis}

All experiments were carried out in triplicates and errors were recorded as standard deviation from the mean. The data were subjected to Duncan's multiple range tests at $p<0.05$ significance level using SPSS version, while some were subjected to $T$ test.

Table 1 Microencapsulation formulation of avocado seed extract and in vitro digestibility of the microcapsule

\begin{tabular}{|c|c|c|c|c|c|c|}
\hline & $\begin{array}{l}\text { Avocado extract } \\
\text { (ml) }\end{array}$ & Gum Arabic & Tween 80 (ml) & Water (ml) & Microcapsule & $\begin{array}{l}\text { In Vitro } \\
\text { digestibility } \\
\text { (mg/g) }\end{array}$ \\
\hline \multicolumn{7}{|c|}{ Corn starch, A (g) } \\
\hline 50 & 5.0 & 0 & 0.5 & 199.5 & $\mathrm{~A} 1$ & \\
\hline 49 & 4.9 & 1.0 & 0.5 & 199.5 & A2 & $23.96 \pm 0.34$ \\
\hline 48 & 4.8 & 2.0 & 0.5 & 199.5 & A3 & \\
\hline \multicolumn{7}{|c|}{ Cassava starch, B (g) } \\
\hline 50 & 5.0 & 0 & 0.5 & 199.5 & B1 & \\
\hline 49 & 4.9 & 1.0 & 0.5 & 199.5 & B2 & $1.04 \pm 0.08$ \\
\hline 48 & 4.8 & 2.0 & 0.5 & 199.5 & B3 & \\
\hline
\end{tabular}




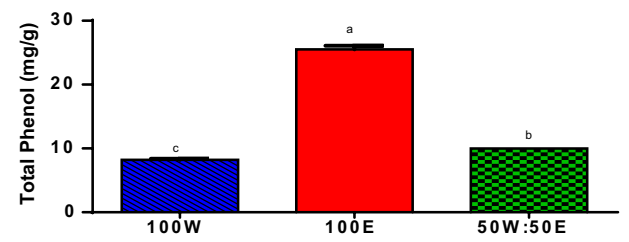

a Total phenolic contents of aqueous, ethanol and aqueous ethanol extracts of Avocado Seed.

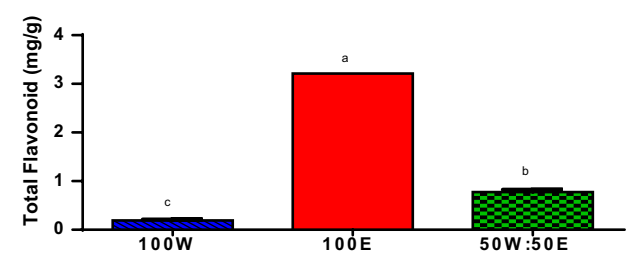

b Total Flavonoid content of aqueous, ethanol and aqueous ethanol extracts of avocado Seed.

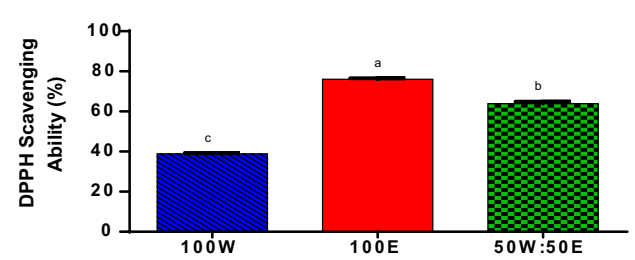

C DPPH free radical scavenging ability of aqueous, ethanol and aqueous ethanol extracts of avocado seed.

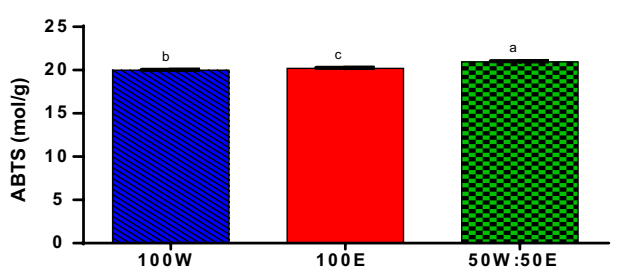

d ABTS activities of ethanol, aqueous and aqueous ethanol extracts of

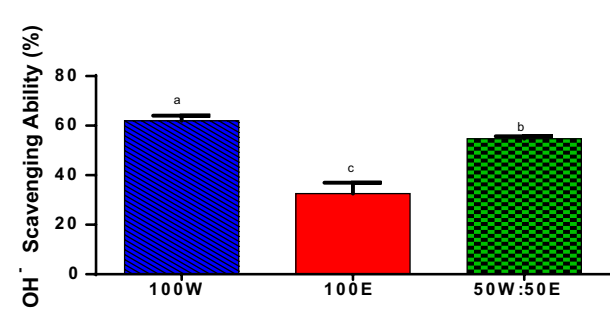

e Hydroxyl ion free radical scavenging ability of aqueous, ethanol and aqueous ethanol extracts of avocado seed.

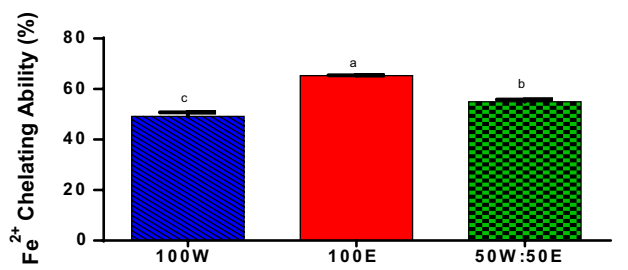

f $\mathrm{Fe}^{2+}$ Chelating activities of aqueous, ethanol, aqueous ethanol extracts of avocado seed.

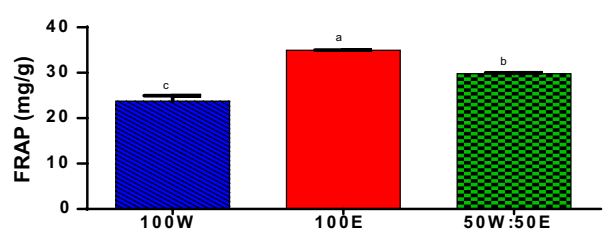

$\mathrm{g}$ FRAP inhibitory activities of aqueous, ethanol and aqueous ethanol extracts of avocado seed.

Keys: 100W: Aqueous extract 100E: Ethanol extract 50E:50W: Aqueous ethanol extract.

Fig.1 a Total phenolic contents of aqueous, ethanol and aqueous ethanol extracts of avocado seed. b Total flavonoid content of aqueous, ethanol and aqueous ethanol extracts of avocado seed. c DPPH free radical scavenging ability of aqueous, ethanol and aqueous ethanol extracts of avocado seed. $\mathbf{d}$ ABTS activities of ethanol, aqueous and aqueous ethanol extracts of avocado seed. e Hydroxyl ion free radical scavenging ability of aqueous, ethanol and aqueous ethanol extracts of avocado seed. $\mathbf{f} \mathrm{Fe}^{2+}$ Chelating activities of aqueous, ethanol, aqueous ethanol extracts of avocado seed. g FRAP inhibitory activities of aqueous, ethanol and aqueous ethanol extracts of avocado seed. Keys: 100 W: Aqueous extract. 100 E: Ethanol extract. 50E:50 W: Aqueous ethanol extract

\section{Results}

\section{Total phenolic and flavonoid contents of avocado seed extracts}

The total phenolic and flavonoid contents of avocado seed extract as influenced by solvents for extraction are shown in Fig. 1a and b, respectively. The total phenol content (TPC) ranged from $8.21 \mathrm{mg} / \mathrm{g}$ in aqueous solution $(100 \mathrm{~W})$ to $25.51 \mathrm{mg} / \mathrm{g}$ in $100 \%$ ethanol (100E). On the other hand, flavonoid content ranged from $3.21 \mathrm{mg} / \mathrm{g}$ in $100 \mathrm{E}$ to $0.19 \mathrm{mg} / \mathrm{g}$ in $100 \mathrm{~W}$.

\section{Antioxidant activities of avocado seed extract}

Figure $1 \mathrm{c}-\mathrm{g}$ present the antioxidant activities of avocado seed extracts using several assays (2, 2-diphenyl-1-picrylhydrazyl (DPPH), 2, 2-Azino-bis (3-ethylbenzthiazoline6-sulphonic acid) (ABTS), Hydroxyl ion $\left(\mathrm{OH}^{-}\right)$, metal Chelating and ferric reducing assays).

\section{Antioxidant properties of microencapsulate}

The results of antioxidant properties of the freshly prepared avocado seed extract microcapsules are shown in Fig. 2a-c. Total phenolic content value ranges 
from $15.0 \mathrm{mg} / \mathrm{g}$ in sample A1 (corn starch cell wall) to $16.70 \mathrm{mg} / \mathrm{g}$ (sample B2) in microcapsule with cassava starch.

\section{Storage stability evaluation of avocado seed extract microencapsulate}

The moisture contents of freshly-prepared microcapsules and after storage at room temperature $\left(27^{\circ} \mathrm{C}\right)$ for 30 days are shown in Fig. 3a. At day 1, the moisture content of the microcapsules ranged from 3.0-3.3\%, while after 30 days, it ranged from 4.2 to $5.4 \%$, indicating a significant increase $(p \leq 0.05)$.

\section{In vitro evaluation of starch digestibility of avocado seed microencapsulate}

The in vitro starch digestibility of microencapsulates is given in Table 1. Corn starch cell wall microcapsule (sample A2) had a higher digestibility $(23.96 \mathrm{mg} / \mathrm{g})$ than $1.04 \mathrm{mg} / \mathrm{g}$ observed in cassava starch cell wall microcapsule (sample B2).

\section{Fourier transform infrared spectroscopy (FTIR) of microencapsulate}

The results of the FTIR for the microcapsules are shown in Fig. 4a and b for corn starch and cassava starch microcapsules, respectively, while spectrum obtained by IR solution software are given in Tables 2 and 3.

\section{Discussion}

These results indicate that $100 \mathrm{E}$ was more effective for the extraction of total phenol and flavonoid in avocado seeds followed by aqueous ethanol, and then $100 \mathrm{~W}$. TPC are important plant constituents with redox properties responsible for antioxidant activities (Aryal 2019). Phenolics are capable of scavenging free radicals, chelate metal catalysts, activating antioxidant enzymes, reducing $\alpha$-tocopherol radicals, and inhibiting oxidases (Amic et al. 2003). Flavonoids are polyphenolic molecules synthesized by plants, they are powerful antioxidants with anti-inflammatory and immune system benefits (Melgar et al. 2018) causing modulation and prevention of oxidation produced by free radicals within the body cells. The TPC and TFC of avocado seed extract indicate that the extracts may possess the antioxidant power needed to reduce the risk of several diseases (Tremocoldi et al. 2018).

The 100E extract had the highest DPPH, $\mathrm{Fe}^{2+}$ Chelation, and FRAP activities. While the aqueous ethanol (50E:50 W) had the highest ABTS activity, the aqueous extract had the highest hydroxyl ion free radical scavenging ability. The best extracting solvent for the bioactive compounds in avocado pear seed, therefore, followed the trend: ethanol $>$ aqueous ethanol $>$ water. Previous studies

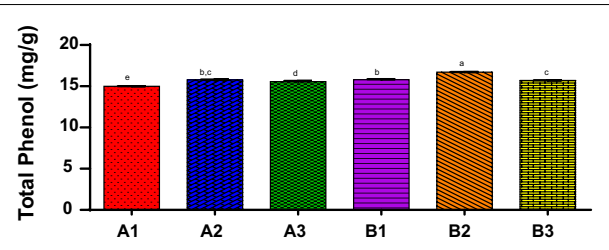

a Total phenol content of encapsulates from avocado seed extract (day1)

Keys: A1: Corn Starch (50g): Gum Arabic (0): Tween $80(0.5 \mathrm{ml})$ : Seed extract $(5 \mathrm{ml})$ A2: Corn Starch (49g): Gum Arabic $(1 \mathrm{~g})$ : Tween $80(0.5 \mathrm{ml})$ : Seed extract $(4.9 \mathrm{ml})$ A3: Corn Starch ( $48 \mathrm{~g})$ : Gum Arabic $(2 \mathrm{~g})$ : Tween $80(0.5 \mathrm{ml})$ : Seed extract $(4.8 \mathrm{ml})$ B1: Cassava Starch (50g): Gum Arabic (0): Tween $80(0.5 \mathrm{ml})$ : Seed extract $(5 \mathrm{ml})$ B2: Cassava Starch (49g): Gum Arabic ( $1 \mathrm{~g})$ : Tween $80(0.5 \mathrm{ml})$ : Seed extract $(4.9 \mathrm{ml})$ B3: Cassava Starch (48g): Gum Arabic (2g): Tween 80 (0.5ml): Seed extract (4.8ml)

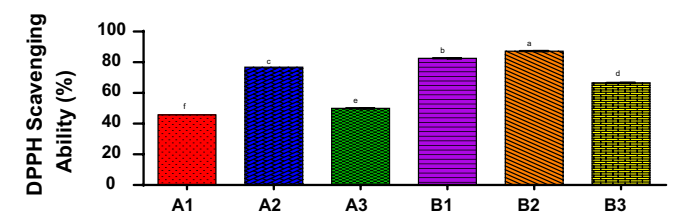

b DPPH free radical scavenging ability of encayplates from avocado seed extract (day 1).

Keys: Al: Corn Starch (50g): Gum Arabic (0): Tween $80(0.5 \mathrm{ml})$ : Seed extract $(5 \mathrm{ml})$ A2: Corn Starch (49g): Gum Arabic (1g): Tween $80(0.5 \mathrm{ml})$ : Seed extract $(4.9 \mathrm{ml})$ A3: Corn Starch (48g): Gum Arabic (2g): Tween $80(0.5 \mathrm{ml})$ : Seed extract $(4.8 \mathrm{ml})$ B1: Cassava Starch (50g): Gum Arabic (0): Tween $80(0.5 \mathrm{ml})$ : Seed extract $(5 \mathrm{ml})$ B2: Cassava Starch (49g): Gum Arabic $(1 \mathrm{~g})$ : Tween $80(0.5 \mathrm{ml})$ : Seed extract $(4.9 \mathrm{ml})$ B3: Cassava Starch (48g): Gum Arabic (2g): Tween $80(0.5 \mathrm{ml})$ : See d extract $(4.8 \mathrm{ml})$

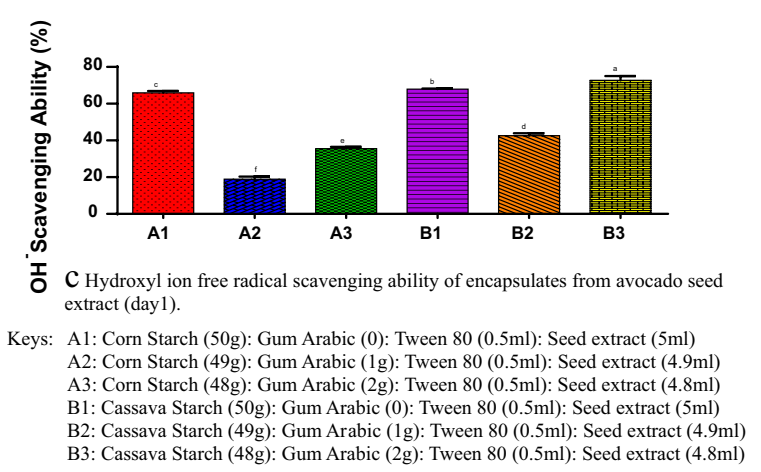

Fig. 2 a Total phenol content of encapsulates from avocado seed extract (day 1). b DPPH free radical scavenging ability of encapsulates from avocado seed extract (day 1). c Hydroxyl ion free radical scavenging ability of encapsulates from avocado seed extract (day 1$)$. Keys: A1: Corn Starch (50 g): Gum Arabic (0): Tween 80 (0.5 ml): Seed extract (5 ml). A2: Corn Starch (49 g): Gum Arabic (1 g): Tween 80 (0.5 ml): Seed extract (4.9 ml). A3: Corn Starch (48 g): Gum Arabic (2 g): Tween 80 (0.5 ml): Seed extract $(4.8 \mathrm{ml})$. B1: Cassava Starch $(50 \mathrm{~g})$ : Gum Arabic (0): Tween 80 (0.5 ml): Seed extract $(5 \mathrm{ml})$. B2: Cassava Starch (49 g): Gum Arabic (1 g): Tween 80 (0.5 ml): Seed extract (4.9 ml). B3: Cassava Starch (48 g): Gum Arabic (2 g): Tween 80 (0.5 ml): Seed extract $(4.8 \mathrm{ml})$

with leaves of kedrostis foetidissima reported methanol as the best solvent for extracts with the highest antioxidant properties in comparison to chloroform and aqueous extract (Pavithra and Vadivukkarasi 2015).. This was attributed to the presence of the hydroxyl group in the phenolic compounds. This may apply to the present study 


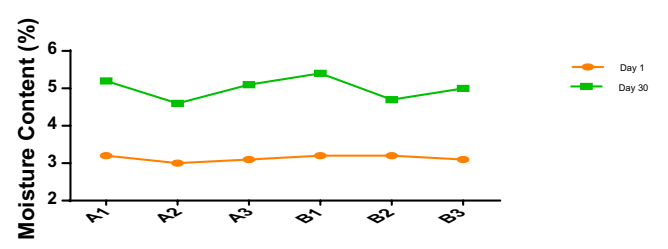

a Moisture content of avocado seed extract microencapsulate

Keys: A1: Corn Starch (50g): Gum Arabic (0): Tween $80(0.5 \mathrm{ml})$ : Seed extract $(5 \mathrm{ml})$ A2: Corn Starch (49g): Gum Arabic (1g): Tween 80 ( $(0.5 \mathrm{ml})$ : Seed extract ( $4.9 \mathrm{ml})$ A3: Corn Starch (48g): Gum Arabic (2g): Tween $80(0.5 \mathrm{ml})$ : Seed extract $(4.8 \mathrm{ml})$ B1: Cassava Starch (50g): Gum Arabic (0): Tween $80(0.5 \mathrm{ml})$ : Seed extract $(5 \mathrm{ml})$ B2: Cassava Starch (49g): Gum Arabic (1g): Tween $80(0.5 \mathrm{ml})$ : Seed extract $(4.9 \mathrm{ml})$ B3: Cassava Starch ( $48 \mathrm{~g})$ : Gum Arabic $(2 \mathrm{~g})$ : Tween $80(0.5 \mathrm{ml})$ : Seed extract $(4.8 \mathrm{ml})$

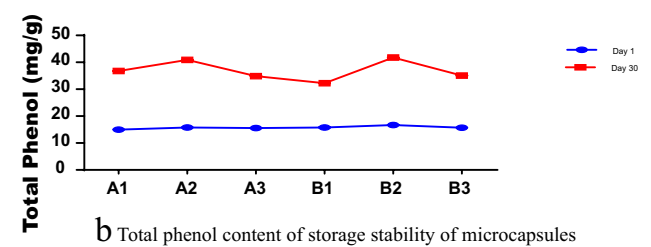

Keys: A1: Corn Starch (50g): Gum Arabic (0): Tween $80(0.5 \mathrm{ml})$ : Seed extract $(5 \mathrm{ml})$ A2: Corn Starch ( $49 \mathrm{~g})$ : Gum Arabic $(1 \mathrm{~g})$ : Tween $80(0.5 \mathrm{ml})$ : Seed extract $(4.9 \mathrm{ml})$ A3: Corn Starch ( $48 \mathrm{~g})$ : Gum Arabic $(2 \mathrm{~g})$ : Tween $80(0.5 \mathrm{ml})$ : Seed extract $(4.8 \mathrm{ml})$ B1: Cassava Starch (50g): Gum Arabic (0): Tween $80(0.5 \mathrm{ml})$ : Seed extract $(5 \mathrm{ml})$ B2: Cassava Starch (49g): Gum Arabic (1g): Tween $80(0.5 \mathrm{ml})$ : Seed extract $(4.9 \mathrm{ml})$ B3: Cassava Starch (48g): Gum Arabic (2g): Tween $80(0.5 \mathrm{ml})$ : Seed extract $(4.8 \mathrm{ml})$

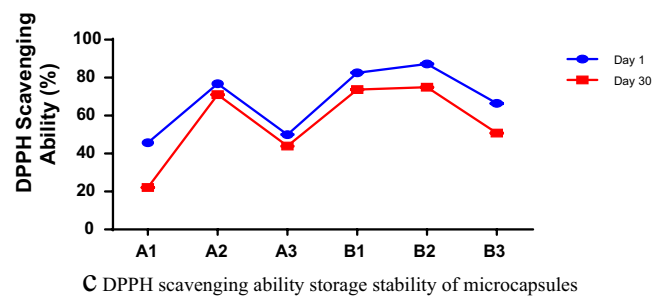

Keys: A1: Corn Starch (50g): Gum Arabic (0): Tween $80(0.5 \mathrm{ml})$ : Seed extract $(5 \mathrm{ml})$ A2: Corn Starch (49g): Gum Arabic (1g): Tween $80(0.5 \mathrm{ml})$ : Seed extract $(4.9 \mathrm{ml})$ A3: Corn Starch (48g): Gum Arabic (2g): Tween $80(0.5 \mathrm{ml})$ : Seed extract $(4.8 \mathrm{ml})$ B1: Cassava Starch (50g): Gum Arabic (0): Tween 80 (0.5ml): Seed extract (5ml) B2: Cassava Starch (49g): Gum Arabic (1g): Tween $80(0.5 \mathrm{ml})$ : Seed extract $(4.9 \mathrm{ml})$ B3: Cassava Starch (48g): Gum Arabic $(2 \mathrm{~g})$ : Tween $80(0.5 \mathrm{ml})$ : Seed extract $(4.8 \mathrm{ml})$

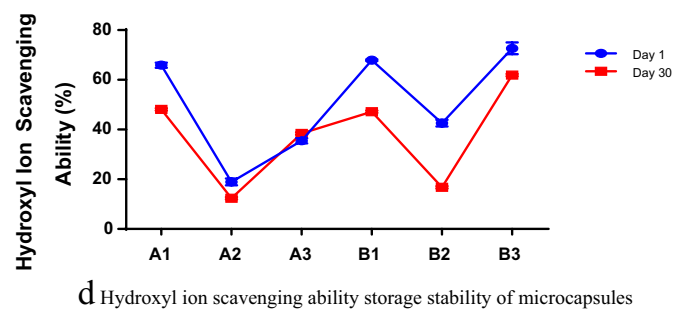

Keys: A1: Corn Starch (50g): Gum Arabic (0): Tween 80 (0.5ml): Seed extract (5ml) A2: Corn Starch (49g): Gum Arabic (1g): Tween $80(0.5 \mathrm{ml})$ : Seed extract $(4.9 \mathrm{ml})$ A3: Corn Starch (48g): Gum Arabic $(2 \mathrm{~g})$ : Tween $80(0.5 \mathrm{ml})$ : Seed extract $(4.8 \mathrm{ml})$ B1: Cassava Starch (50g): Gum Arabic (0): Tween $80(0.5 \mathrm{ml})$ : Seed extract $(5 \mathrm{ml})$ B2: Cassava Starch (49g): Gum Arabic $(1 \mathrm{~g})$ : Tween $80(0.5 \mathrm{ml})$ : Seed extract $(4.9 \mathrm{ml})$ B3: Cassava Starch $(48 \mathrm{~g})$ : Gum Arabic $(2 \mathrm{~g})$ : Tween $80(0.5 \mathrm{ml})$ : Seed extract $(4.8 \mathrm{ml})$

since methanol has the same functional group as ethanol. Furthermore, the poisonous nature of both methanol and chloroform make ethanol the best option for solvent extraction of the bioactive compounds in avocado pear seed. However, all three extracts used in the present study showed considerably high antioxidant activities
Fig. 3 a Moisture content of avocado seed extract microencapsulate b Total phenol content of storage stability of microcapsules. c DPPH scavenging ability storage stability of microcapsules. $\mathbf{d}$ Hydroxyl ion scavenging ability storage stability of microcapsules. Keys: A1: Corn Starch (50 g): Gum Arabic (0): Tween 80 (0.5 ml): Seed extract (5 ml). A2: Corn Starch (49 g): Gum Arabic (1 g): Tween 80 (0.5 ml): Seed extract ( $4.9 \mathrm{ml})$. A3: Corn Starch (48 g): Gum Arabic $(2 \mathrm{~g})$ : Tween 80 (0.5 ml): Seed extract ( $4.8 \mathrm{ml})$. B1: Cassava Starch ( $50 \mathrm{~g})$ : Gum Arabic (0): Tween 80 (0.5 ml): Seed extract ( $5 \mathrm{ml})$. B2: Cassava Starch (49 g): Gum Arabic (1 g): Tween 80 (0.5 ml): Seed extract $(4.9 \mathrm{ml})$. B3: Cassava Starch (48 g): Gum Arabic (2 g): Tween 80 (0.5 ml): Seed extract (4.8 ml)

and may serve as potential sources for protection against oxidative stress (Araujo et al. 2018).

The values were significantly different $(p \leq 0.05)$ from each other (Fig. 2a). Compared to $100 \%$ ethanolic extract which was used for the microcapsule, there was about $50 \%$ retention of phenolic compound in the microcapsules. Kuck et al. (2017) also reported such reduction in frozen and spray-dried Bordo grape skin extract microparticles. The reduction in the phenolic content of microcapsule when compared with that of the extract used may be attributed to the effect of homogenization, freeze-drying and interaction of the phenol with the hydroxyl group of wall material used (starch and gum Arabic) (Özbek and Ergönül 2020).

The 2, 2-diphenyl-1-picrylhydrazyl (DPPH) radicals (Fig. 2b) scavenging ability of encapsulating of corn starch microcapsule (A) ranged from $45.69 \%$ in A1 to $76.79 \%$ in A2, while cassava starch microcapsule (B) ranged from $66.42 \%$ in $\mathrm{B} 3$ to $87.22 \%$ in $\mathrm{B} 2$. DPPH scavenging ability of the microcapsules were significantly $(p \leq 0.05)$ higher in cassava starch cell wall material samples (B1, B2 and B3) than those of corn starch cell wall materials (A1, A2 and A3). The higher DPPH scavenging ability of cassava starch wall material microcapsules may be attributed to the synergistic activities of some antioxidant compounds also present in cassava (Mehran et al. 2014). There was a slight reduction in the DPPH activity of the microcapsules compared to the avocado fresh extracts. Generally, the decrease in DPPH scavenging ability of microcapsule as compared with that of the fresh extract could be as a result of the decrease in the phenol content, the same trend was also reported by Flores et al. (2014).

The ability of the microcapsules to prevent $\mathrm{Fe}^{2+}$ / $\mathrm{H}_{2} \mathrm{O}_{2}$ induced decomposition of deoxyribose had its highest degrading ability for corn starch microcapsule at $66 \%$ in $\mathrm{A} 1$ and the least at $19 \%$ in $\mathrm{A} 2$, while cassava starch microencapsulate (B1, B2, B3) had its highest degradation ability at $73 \%$ in $\mathrm{B} 3$ and the least at $43 \%$ in $\mathrm{B} 2$ (Fig. 2c). This indicates microcapsules with corn starch cell wall had the least $\mathrm{OH}^{-}$scavenging ability, while 


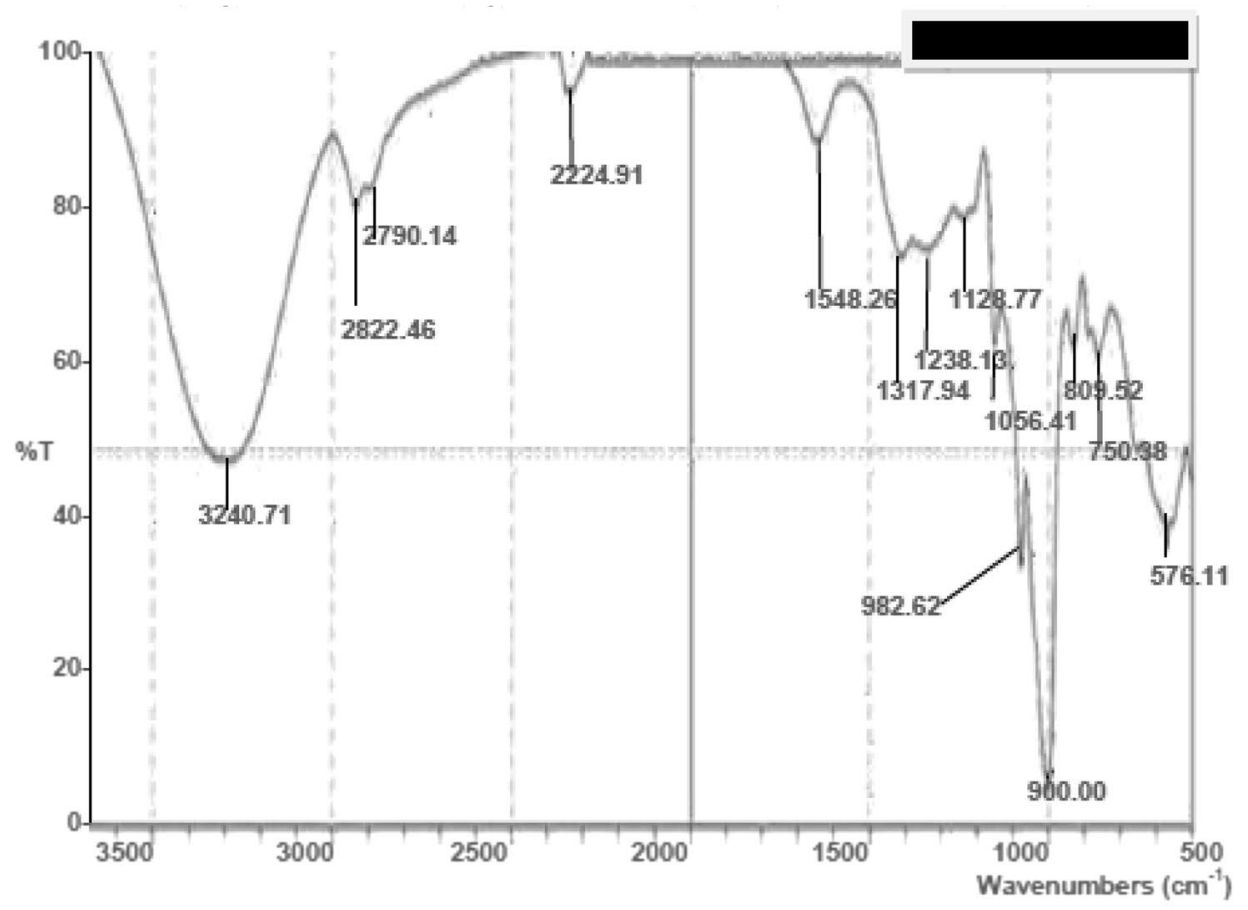

a FT-IR Spectra of Corn Starch Microencapsulate

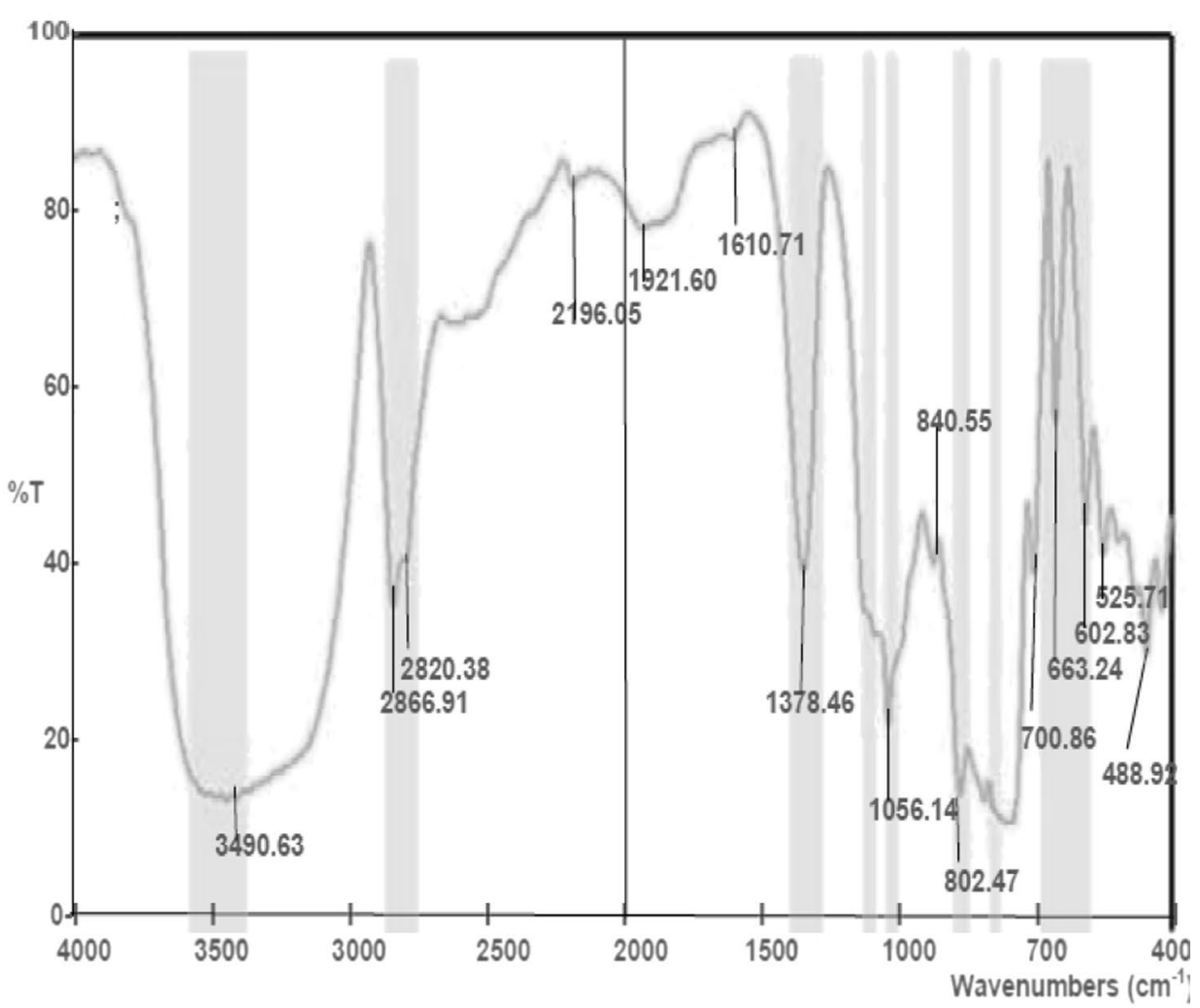

b FT-IR Spectra of Cassava Starch Microencapsulate

Fig. 4 a FT-IR spectra of corn starch microencapsulate. b FT-IR spectra of cassava starch microencapsulate 
Table 2 FTIR analysis spectra for corn starch (A2) microcapsules

\begin{tabular}{lllll}
\hline Run (corn starch) & Absorption $\left(\mathbf{c m}^{-}{ }^{\mathbf{1}}\right)$ & Appearance & Group & Compound class \\
\hline 1 & 3240.71 & Strong broad & $\mathrm{O}-\mathrm{H}$ stretching & Alcohol, Carboxylic acid \\
2 & 2822.46 & Medium & $\mathrm{CH}_{2}$ stretching vibration & Alkane \\
3 & 2790.14 & Medium & $\mathrm{C}=$ O stretching vibration & Aldehyde \\
4 & 2224.91 & Weak & $\mathrm{O}-\mathrm{H}$ bending & Alkyne \\
5 & 1548.26 & Medium & $\mathrm{CH}_{2}$ bending & Alkane \\
\hline
\end{tabular}

Table 3 FTIR analysis spectra for cassava starch (B2) microcapsules

\begin{tabular}{lllll}
\hline Run (Cassava starch) & Absorption $\left(\mathbf{c m}^{-}{ }^{\mathbf{}}\right.$ ) & Appearance & Group & Compound class \\
\hline 1 & 3490.63 & Strong broad & O-H stretching & Alcohol \\
2 & 2866.91 & Medium & C-H stretching vibration & Alkane \\
3 & 2820.38 & Medium & C $\equiv$ C stretching & Aldehyde \\
4 & Weak & C $\equiv$ C stretching & Aldehyde \\
5 & 196.05 & C-H stretching vibration & Aromatic compound \\
6 & 1921.60 & C=O stretching vibration & a, $\beta$ unsaturated ketone \\
\hline
\end{tabular}

microcapsules with cassava starch cell wall material had the highest., the result obtained shows that each encapsulate hydroxyl radical decreases after encapsulation but with $\mathrm{A} 2$ possesses a higher superoxide radical scavenging capacity than $\mathrm{B} 2$ by its ability to prevent the least induced hydrogen peroxide $\left(\mathrm{H}_{2} \mathrm{O}_{2}\right)$ by superoxide dismutase into hydroxyl radicals $\left(\mathrm{OH}^{*}\right)$ via the Fenton or Haber-Weiss reactions (Cannizzo et al. 2011).

Therefore, encapsulate with antioxidant activity against the DPPH radical scavenging ability and a superior hydroxyl free radical scavenging ability to the least hydroxyl radical induced by decomposition of deoxyribose may be A2 microcapsule.

The increase in moisture content may suggest that microcapsules absorbed moisture from the environment due to the hydrophilic nature of starch granules (Wang et al. 2019). However, the moisture contents are still within the acceptable range limit $(<10)$ as recommended by WHO (2003).

The total phenolic content of samples stored for 30 days (Fig. 3b) showed that values for samples with corn starch cell wall material (A) ranged from 34.87-40.91 mg/g, while those for cassava starch cell wall material (B) ranged from $32.22-41.76 \mathrm{mg} / \mathrm{g}$. The microcapsules exhibited increased phenolic content after storage for 30 days. These increases have been observed in other studies and are attributed to the ability of these compounds to react with each other and hydrolyze to smaller molecules (Sun-Waterhouse et al 2013). Other factors reported to having influenced such increase include the chemical structures of the phenolic compounds, the matrix in which they are dispersed, physicochemical characteristics of the powders, such as surface area, processing and storage conditions may result in increased phenolic content (Sun-Waterhouse et al 2013).

The DPPH scavenging ability of the microcapsules after 30 days' storage ranged from $22-71 \%$ and $51-75 \%$ for samples with corn (A) and cassava (B) starch cell wall, respectively (Fig. 3c). The radical scavenging ability of sample B2 was significantly $(p<0.05)$ higher than other encapsulate. Results also showed about $20 \%$ reduction in DPPH of the microcapsules after 30 days storage. This reduction could be as a result of the microencapsulation which prevented the deterioration of the core materials.

Also, the ability of the sample microcapsules to prevent $\mathrm{Fe}^{2+} / \mathrm{H}_{2} \mathrm{O}_{2}$ induced decomposition of deoxyribose (Fig. 3d) was reduced at 30 days. The decomposition of deoxyribose ability of the corn starch microencapsulate (A1, A2, A3) had its degradation ability at 48\% in $\mathrm{A} 1$ and the least degradation ability at $12 \%$ in A2 while samples with cassava starch microencapsulate (B1, B2, B3) had its degradation ability at $62 \%$ in $\mathrm{B} 3$ and the least at $17 \%$ in B2. The least activities is found in sample A2. This is an indication that sample A2 will display a higher superoxide radical scavenging capacity than other samples by preventing the convection of the least hydrogen peroxide $\left(\mathrm{H}_{2} \mathrm{O}_{2}\right)$ form in the body cells by superoxide dismutase into hydroxyl radicals $\left(\mathrm{OH}^{*}\right)$ via the Fenton or Haber-Weiss reactions (Cannizzo et al. 2011).

The results of antioxidant capacity of the different avocado encapsulate obtained in this study after 30 days 
of storage showed that there is a significant increase in phenolic composition with a decrease in their DPPH and hydroxyl free radical scavenging ability. However, sample A2 possesses a superior hydroxyl free radical scavenging ability of $12 \%$ than the other encapsulates by the ability to prevent convection of least hydrogen peroxide $\left(\mathrm{H}_{2} \mathrm{O}_{2}\right)$ form in the body cells via Fenton reactions. Thus, this makes A2 the best encapsulated with superior antioxidant activity.

Corn starch cell wall microcapsule (sample A2) had a higher digestibility $(23.96 \mathrm{mg} / \mathrm{g})$ than $1.04 \mathrm{mg} / \mathrm{g}$ observed in cassava starch cell wall microcapsule (sample B2). This may be attributed to the smaller molecular weight of corn starch which might have contributed to the higher digestibility (Waterschoot et al. 2015; Zue et al. 2015) of sample A2 as compared to sample B2. The increase in the utilization of corn starch in food and medicine has been linked to its mineral richness, availability, low cost, biodegradability and hydrophilicity which allow the starch to be easily broken down by enzymes in the digestive tract (Waterschoot et al. 2015). However, the low in vitro digestibility of cassava starch microcapsule may be useful in the production of microcapsules that would not be easily degraded by hydrolytic enzymes, thereby ensuring shelf stability. Some studies have confirmed that the behavior of encapsulates is always dependent on the surrounding matrix composition and their resistance or susceptibility molecular materials with abundant natural reserve and biodegradability (Zue et al. 2015).

Sample A2 (corn starch cell wall microcapsules) and B2 (cassava starch cell wall microcapsules) with the highest antioxidant activities were selected for FTIR analysis. The major functional groups in sample A2 were $\mathrm{O}-\mathrm{H}$ (3240.17), $\mathrm{C}=\mathrm{O}$ (2790.91), ring (750.38) and $\mathrm{C} \equiv \mathrm{C}$ (2224.91) indicating alcohol, carbonyl, benzene ring and alkyne groups respectively). In sample B2, the functional groups were $\mathrm{O}-\mathrm{H}$ (3490.63), $\mathrm{C}=\mathrm{O}$ (2820.38), ring (700.86) and $\mathrm{C}=\mathrm{C}$ (1610.71) indicating alcohol, carbonyl, benzene ring and alkene groups, respectively. Benzene ring with $\mathrm{OH}$ group is an indication of the presence of polyphenols. Polyphenols are natural compounds characterized by the presence of resorcinol (benzene ring with several hydroxyl groups), catechol and phenol (Liana et al. 2020). Carbonyl group is also an indication of the presence of phenolic acid.

\section{Conclusions}

The study established that avocado seed contained appreciable amount of bioactive compounds. The ethanolic avocado seed extract exhibited superior free radical scavenging abilities over encapsulate. Although there was slight reduction in DPPH and hydroxyl free radical scavenging ability of encapsulates after 30 days of storage, the encapsulate had moisture contents that were shelf stable, less than maximum acceptable allowable limit for moisture content $(<10)$. However, cassava starch was a better cell wall material for the microencapsulation of avocado seeds extract. The in vitro starch digestibility was higher in corn than in cassava starch cell wall materials. The FTIR indicated that the primary functional groups in microcapsules were $\mathrm{OH}$, $\mathrm{C}=\mathrm{O}$, benzene ring and $\mathrm{C} \equiv \mathrm{C}$.

\section{Abbreviations}

FTIR: Fourier-transform infrared spectroscopy; $\mathrm{O}-\mathrm{H}$ : Hydroxyl group; $\mathrm{C}=\mathrm{O}$ : Carbonyl group; C $\equiv$ C: Alkyne group; DPPH: 2, 2- Diphenyl-1-picryhydrazyl; ABTS: 2,2'-Azino-bis(3-ethylbenzothiazoline-6-sulfonic acid; $\mu$ L: Microliter;

TMW: Molecular mass of Trolox; TBA: Thiobarbituric acid; FRAP: Ferric reducing antioxidant power.

\section{Authors' contributions}

OOA designed the research, monitored the research execution, interpreted data, carried out statistical analyses, and read and corrected manuscript drafts. ETF co-designed the research, carried out laboratory and statistical analyses, and wrote the manuscript. OAA revised and corrected the manuscript draft. HNA revised and corrected the manuscript draft. AlO co-designed the manuscript. All authors have read and approved the manuscript.

\section{Funding}

No funding was received for this research work.

Availability of data and materials

Data are available on request.

\section{Declarations}

Ethical approval and consent to participate

The study protocol was approved by the Ethical Committee School of Agriculture and Agricultural Technology, Federal University of Technology, Akure, Nigeria (FUTA/SAAT/2020/016). Verbal consent to participate was obtained from the sensory panelist who participate in sensory evaluation.

Consent for publication

Not applicable.

\section{Competing interests}

No competing interest within authors.

\section{Author details}

${ }^{1}$ Department of Food Science and Technology, Federal University of Technology, Akure, Nigeria. ${ }^{2}$ Department of Food Science and Technology, Ondo State University of Science and Technology, Okitipupa, Nigeria.

Received: 9 December 2021 Accepted: 27 January 2022 Published online: 19 February 2022

\footnotetext{
References

Amic D, Davidovic-Amic D, Beslo D, Trinajstic N (2003) Structure related scavenging activity relationship of flavonoids. Croatia Chem Act 76:55-61

Araújoa RG, Rodriguez-Jassoa RM, Héctor A, Manuela RM, Noé AP, C. (2018) Avocado by-products: nutritional and functional properties. Trends Food Sci Technol 80:51-60

Aryal S, Baniya MK, Danekhu K, Kunwar P, Gurung R, Koirala N (2019) Total phenolic content, flavonoid content and antioxidants potential of wild
} 
vegetables from Western Nepal. Plants (basel) 8(4):96. https://doi.org/10. 3390/plants8040096

Association of Official Analytical Chemist (AOAC) (2012) Official methods of analysis of the analytical chemist international, 18th edn. Gaithersburg, MD USA

Awolu OO, Manohar B (2019) Quantitative and qualitative characterization of mango kernel seed oil extracted using supercritical $\mathrm{CO} 2$ and solvent extraction techniques. Heliyon 5(12):e03068

Awolu O, Oladeji O (2021) Natural plant pigments and derivatives in functional foods developments. Eur J Food Sci Technol 5(1):25-40

Awolu OO, Osemeke RO, Ifesan BOT (2016) Antioxidant, functional and rheological properties of optimized composite flour, consisting wheat and amaranth seed, brewers'spent grain and apple pomace. J Food Sci Technol 53(2):1151-1163

Awolu OO, Osigwe MA (2019) Nutritional and antioxidant potential of rice flour enriched with kersting's groundnut (Kerstingiella geocarpa) and lemon pomace. Int J Food Stud 8(1)

Awolu OO, Obafaye RO, Ayodele BS (2013) Optimization of solvent extraction of oil from neem (Azadirachta indica) and its characterizations. J Sci Res Rep, pp 304-314

Ayala-Zavala JF, Vega-Vega V, Rosas-Domínguez C, Palafox-Carlos H, Villa Rodriguez JA, Siddiqui MW, Dávila-Aviña JE, González-Aguilar GA (2011) Agroindustrial potential of exotic fruit byproducts as a source of food additives. Food Res Int 44:1866-1874

Bao J, Cai Y, Sun M, Wang G, Corke H (2005) Anthoctanins, flavonoids, and free radical scavenging activity of Chinese bayberry (Myricarubra) extracts and their color properties and stability. J Agric Food Chem 53(6):2327-2332. https://doi.org/10.1021/jf048312z

Cannizzo ES, Clement C, Sahu R, Follo C, Santambrogio L (2011) Oxidative stress, inflamm-aging and immunoenescence. J Proteom 74(11):2313-2323. https://doi.org/10.1016/jprot.2011.06.005

Ding H, Chin YW, Kinghorn Aoil D, D'Ambrosio SM (2007) Chemopreventive characteristics of avocado fruit. Cancer Biol 17:386-394

Englyst HN, Kingman SM, Cummings JH (1992) Classification and measurement of nutritionally important starch fractions. Eur J Clin Nutr 46:33-50

Flores FP, Singh RK, Kerr WL, Pegg RB, Kong F (2014) Total phenolics content and antioxidant capacities of microencapsulated blueberry anthocyanins during in vitro digestion. Food Chem 153:272-278

Gyamfi MA, Yonamine M, Aaniya Y (1999) Free Radical scavenging action of medicinal herbs from Ghana: thonningia sanguine on experimentally induced liver injuries. Gen Pharmacol 32:661-667

Halliwell B, Gutteridge JM (1981) Formation of a thiobarbituric-acid-reactive substance from deoxyribose in the presence of iron salts: the role of superoxide and hydroxyl radicals. Letters 128:347-352

Kuck LS, Wesolowski JL, Noreña CP (2017) Effect of temperature and relative humidity on stability following simulated gastro-intestinal digestion of microcapsules of Bordo grape skin phenolic extract produced with different carrier agents. Food Chem 230:257-264

Liana CS, Alina U, Cristiana-Adela L, Maria F, Janna C, Oana LP, Carmen RP, Mihaela AR, Mirandeli B, Claudia VG (2020) Valuable food molecules with potential benefits for human health. http://www.intechopen.com/chapters/71141.

Lu QY, Arteaga JR, Zhang Q, Huerta S, Go VL, Heber D (2005) Inhibition of prostate cancer cell growth by an avocado extract: role of lipid-soluble bioactive substances. J Nutr Biochem 16:23-30

Mehran MJ, Zendehbad SH, Malla SUDHAKAR (2014) Free radical scavenging and antioxidant potential activity of cassava plants. Asian J Pharmaceut Clin Res 7(1):66-70

Melgar B, Dias MI, Ciric A, Sokovic M, Garcia-Castello EM, Rodriguez-Lopez AD (2018) Bioactive characterization of Persea americana Mill. by-products: a rich source of inherent antioxidants. Ind Crops Prod 111:212-218

Melo PS, Massarioli AP, Denny C, dos Santos LF, Franchin M, Pereira GE (2015) Winery by-products: extraction optimization, phenolic composition and cytotoxic evaluation to act as a new source of scavenging of reactive oxygen species. Food Chem 181:160-169

Naczk M, Shahidi F (2006) Phenolics in cereals, fruits and vegetables: occurrence, extraction and analysis. J Pharmacol Biomed Anal 41:1523-1542

Naik SN, Goud W, Rout PK, Dalai AK (2010) Production of first and second generation biofuels: a comprehensive review. Renew Sustain Energy Rev 14:578-597

Ogundele OM, Awolu OO, Badejo AA, Nwachukwu ID, Fagbemi TN (2016) Development of functional beverages from blends of Hibiscus sabdariffa extract and selected fruit juices for optimal antioxidant properties. Food Sci Nutr 4(5):679-685

Özbek ZA, Ergönül PG (2020) Optimisation of wall material composition of freeze-dried pumpkin seed oil microcapsules: Interaction effects of whey protein, maltodextrin, and gum Arabic by D-optimal mixture design approach. Food Hydrocoll 107:105909

Panche A, Chandra S, Diwan A, Harke S (2015) Alzheimer's and current therapeutics: a review. Asian J Pharm Clin Res 8:14-19

Pavithra K, Vadivukkarasi S (2015) Evaluation of free radical scavenging activity of various extracts of leaves from Kedrostis foetidissima (Jacq) Cogn. Food Sci Hum Wellness 4(1):42-46

Pulido R, Bravo L, Saura-Calixto F (2003) Antioxidant activity of dietary polyphenols as determined by a modified ferric reducing/antioxidant power assay. J Agric Food Chem 48:3396-3402

Puntel RL, Nogueira CW, Rocha JB (2005) Krebs cycle intermediates modulate thiobarbituric acid reactive species (TBARS) production in rat brain, in vitro. Neurochem Res 30:225-235

Re RN, Pellegrini A, Proteggente A, Pannala M, Rice-Evans C (1999) Antioxidant activity applying an improved ABTS radical cation decolorization assay. Free Radic Biol Med 26:1231-1237

Saavedra J, Córdova A, Navarro R, Díaz-Calderón P, Fuentealba C, Astudillo-Castro C, Toledo L, Enrione J, Galvez L (2017) Industrial avocado waste: functional compounds preservation by convective drying process. J Food Eng 198:81-90

Sangeeta S, Nikhil KM, Charu LM (2015) Optimisation of phenolic extraction from Averrhoa Carambola Pomace by response surface methodology and its microencapsulation by spray and freeze drying. Food Chem 171:144-152

Segovia FJ, Corral-Pérez JJ, Almajano MP (2016) Avocado seed: Modeling extraction of bioactive compounds. Ind Crops Prod 85:213-220

Sharma K, Mahato N, Cho MH, Lee YR (2017) Converting citrus wastes into value added products: economic and environmently friendly approaches. Nutrition 34:29-46

Singleton VL, Orthofer R, Lamuela RM (1999) Analysis of total phenols and other oxidation substrates and antioxidants by means of Folin-Ciocalteu reagent. Methods Enzymol 299:152-178

Sun-Waterhouse D, Zhou J, Miskelly GM, Wibisono R, Wadhwaa SS (2013) Stability of encapsulated olive oil in the presence of caffeic acid. Food Chem 126:1049-1056

Tremocoldi MA, Rosalen PL, Franchin M, Massarioli AP, Denny C, Daiuto EÂ (2018) Exploration of avocado by-products as natural sources of bioactive compounds. PLOS ONE 13:1-12

Wang Y, Zhang R, Ahmed S, Wen and Liu, Y, (2019) Preparation and characterization of corn starch bio-active edible packaging films based on zein incorporated with orange-peel oil. Antioxidants 8:391

Waterschoot J, Gomand SV, Fierens E, Delcour JA (2015) Production, structure, physicochemical and functional properties of maize, cassava, wheat, potato and rice starches. Starch-Starke 67:14-29

WHO (2003) Post-harvest and processing technology of staple food Technical Compendium, WHO, Agricultural Science. Bulletin 88:171-172

Zuo YF, Gu JY, Tan HY, Zhang YH (2015) Thermoplastic Starch Prepared with different plasticizers: Relation between degree of plasticization and properties. Mater Sci 30:423-428

\section{Publisher's Note}

Springer Nature remains neutral with regard to jurisdictional claims in published maps and institutional affiliations. 